\title{
ANALISIS PEMBENTUKAN PORTOFOLIO OPTIMAL SAHAM MENGGUNAKAN METODE MULTIOBJEKTIF
}

\author{
Dwi Nining Indrasari, Neva Satyahadewi, Hendra Perdana
}

\begin{abstract}
INTISARI
Strategi yang dapat dilakukan investor dalam berinvestasi, yaitu dengan membentuk portofolio optimal. Portofolio optimal dapat dibentuk menggunakan metode multiobjektif, dimana metode tersebut dapat memaksimalkan return dan meminimalkan risiko pada waktu bersamaan. Pada metode multiobjektif terdapat koefisien pembobot yang digunakan untuk menunjukkan seberapa besar seorang investor mengambil risiko atas expected return. Tujuan dari penelitian ini adalah menganalisis besarnya nilai return dan risiko yang terbentuk dalam pembentukan portofolio optimal saham menggunakan metode multiobjektif. Data yang digunakan dalam penelitian merupakan data penutupan harga saham harian yang selalu masuk dalam indeks saham LQ-45 pada periode 1 Januari sampai dengan 31 Desember 2018. Saham yang dipilih untuk pembentukan portofolio optimal ada empat saham, diantaranya PTBA.JK, BBCA.JK, ICBP.JK, dan SMGR.JK. Pada kasus ini diambil contoh dengan menginvestasikan modal sebesar Rp50.000.000,00 dengan periode waktu 20 hari dan tingkat kepercayaan 95\%. Berdasarkan hasil analisis menggunakan koefisien pembobot $k=10$, maka diperoleh nilai return sebesar Rp4.962.680,00 dengan risiko sebesar Rp4.352.279,00.
\end{abstract}

Kata Kunci: Metode Multiobjektif, Portofolio Optimal, Koefisien Pembobot

\section{PENDAHULUAN}

Investasi merupakan kegiatan penanaman harta maupun modal dengan tujuan memperoleh keuntungan dimasa yang akan datang. Investor dapat melakukan investasi dalam sektor riil maupun sektor keuangan. Salah satu sektor keuangan yang paling diminati oleh masyarakat adalah saham. Saham merupakan instrumen investasi yang banyak dipilih investor karena saham mampu memberikan tingkat keuntungan yang menarik[1]. Dua hal yang akan dihadapi oleh investor ketika melakukan investasi, yaitu return dan risiko. Keduanya memiliki hubungan antara besarnya return dan risiko. Semakin besar return yang diharapkan, maka semakin besar pula risiko yang dihadapi.

Salah satu bentuk pengukuran nilai risiko dalam berinvestasi adalah Value at Risk (VaR). VaR merupakan alat ukur untuk menghitung kerugian yang dapat terjadi dengan mengetahui posisi aset berdasarkan tingkat kepercayaan tertentu[2]. Investor dapat mengurangi risiko investasi dengan membentuk suatu portofolio saham yang optimal. Portofolio optimal merupakan portofolio yang dipilih seorang investor dari sekian banyak pilihan yang ada pada kumpulan portofolio efisien. Portofolio efisien merupakan portofolio-portofolio yang baik, tetapi bukan yang terbaik. Hanya ada satu portofolio terbaik, yaitu portofolio optimal[3].

Konsep portofolio optimal yang dicetuskan oleh Markowitz merupakan pengoptimalan portofolio yang ditujukan untuk investor standar karena hanya mengacu pada satu penjelasan dari return portofolio[4]. Pada penelitian ini pembentukan portofolio optimal saham difokuskan dengan menggunakan metode multiobjektif. Metode multiobjektif merupakan suatu metode dalam pembentukan portofolio optimal saham yang bersifat memaksimalkan return dan meminimalkan risiko pada waktu yang bersamaan, serta menawarkan beberapa alternatif investasi tergantung pada preferensi investor.

Tujuan dari penelitian ini adalah untuk menganalisis besarnya nilai return dan risiko yang terbentuk dalam pembentukan portofolio optimal saham menggunakan metode multiobjektif. Data yang 
digunakan merupakan data sekunder, yaitu data penutupan harga saham harian yang selalu masuk dalam indeks saham LQ-45 pada periode 1 Januari sampai dengan 31 Desember 2018. Saham yang dipilih terdapat empat saham, diantaranya PTBA.JK, BBCA.JK, ICBP.JK, dan SMGR.JK. Pemilihan saham tersebut berdasarkan nilai expected return positif tertinggi. Koefisien pembobot $k=10$ digunakan untuk pembentukan portofolio optimal.

\section{RETURN SAHAM}

Investasi memiliki tujuan yaitu memaksimalkan return tanpa melupakan faktor risiko yang harus ditanggung. Return merupakan imbalan atas keberanian investor dalam menanggung risiko atas investasi yang dilakukan, sehingga return menjadi faktor yang memotivasi investor untuk berinvestasi. Return dapat berupa realized return dan expected return[5]. Realized return merupakan return yang telah terjadi yang dihitung berdasarkan data historis. Realized return saham dinyatakan dalam rumus sebagai berikut[6]:

$$
R_{i t}=\ln \left(\frac{S_{i t}}{S_{i(t-1)}}\right)
$$

dimana:

$$
\begin{aligned}
& i=1,2,3, \ldots, m \\
& t=1,2,3, \ldots, n
\end{aligned}
$$

dengan:

$R_{i(t)}$ adalah return saham $i$ pada periode ke- $t$

$S_{i t}$ adalah data harga saham $i$ pada periode ke- $t$

$S_{i(t-1)}$ adalah harga saham $i$ pada periode ke- $(t-1)$

Expected return adalah return yang diharapkan oleh investor dimasa mendatang. Expected return saham dinyatakan dalam rumus sebagai berikut[7]:

$$
\mu_{i}=\frac{\sum_{t=1}^{n} R_{i t}}{n}
$$

dengan:

$\mu_{i}$ adalah expected return saham $i$

$n$ adalah jumlah periode saham $i$

\section{VOLATILITAS RETURN SAHAM}

Volatilitas return saham yang dinyatakan dengan $(\sigma)$ merupakan standar deviasi dari log return saham pada periode tahunan. Volatilitas ini digunakan untuk mengukur tingkat risiko dari suatu saham. Nilai volatilitas berada pada interval yang positif, yaitu 0 sampai tak hingga $(0 \leq \sigma \leq \infty)$. Nilai volatilitas yang tinggi menunjukkan bahwa harga saham berubah (naik dan turun) dengan range yang sangat lebar. Sedangkan, nilai volatilitas dikatakan rendah jika harga saham jarang berubah atau cenderung konstan[8].

Salah satu metode untuk mengestimasi volatilitas return saham adalah volatilitas historis, yaitu volatilitas yang dihitung berdasarkan pada harga-harga masa lalu. Volatilitas return saham dinyatakan dalam rumus sebagai berikut[6]:

$$
\sigma_{i}=\sqrt{\text { jumlah hari perdagangan } \times \frac{\sum_{t=1}^{n}\left(R_{i t}-\mu_{i}\right)^{2}}{n-1}}
$$

dengan: 
$\sigma_{i}$ adalah volatilitas return saham $i$

$n$ adalah jumlah periode saham $i$

\section{UJI NORMALITAS KOLMOGOROV-SMIRNOV}

Salah satu teknik yang digunakan untuk menguji apakah data berdistribusi normal adalah uji Kolmogorov-Smirnov (K-S). Konsep dasar uji Kolmogorov-Smirnov adalah membandingkan distribusi teoritik dan distribusi empirik (observasi) berdasarkan frekuensi kumulatif[9].

Hipotesis pada uji Kolmogorov-Smirnov adalah sebagai berikut[9]:

$H_{0}: F(x)=F_{0}(x)$ untuk semua $x \quad$ (data berdistribusi normal)

$H_{1}: F(x) \neq F_{0}(x)$ untuk semua $x \quad$ (data tidak berdistribusi normal)

dengan statistik uji:

$$
D=\max \left|F_{0}(x)-S_{N}(x)\right|
$$

dengan:

$F_{0}(x)$ adalah fungsi distribusi frekuensi kumulatif teoritis

$S_{N}(x)$ adalah fungsi distribusi frekuensi kumulatif yang diamati dari suatu sampel random dengan $n$ observasi

\section{PORTOFOLIO}

Portofolio adalah suatu kumpulan aktiva keuangan dalam suatu unit yang dipegang atau dibuat oleh seorang investor, perusahaan investasi, atau institusi keuangan[10]. Expected return portofolio merupakan rata-rata dari expected return masing-masing saham yang ada dalam portofolio. Expected return portofolio dapat ditulis sebagai berikut [11]:

$$
\mu_{p}=\sum_{i=1}^{m}\left(\mu_{i} w_{i}\right)
$$

dengan:

$\mu_{p}$ adalah expected return portofolio

$w_{i}$ adalah bobot saham $i$

Dalam bentuk notasi matriks, expected return portofolio pada Persamaan (5) dapat ditulis sebagai berikut[12]:

$$
\boldsymbol{\mu}_{p}=\mu_{1} w_{1}+\mu_{2} w_{2}+\ldots+\mu_{n} w_{n}=\left[\begin{array}{llll}
\mu_{1} & \mu_{2} & \ldots & \mu_{n}
\end{array}\right]\left[\begin{array}{c}
w_{1} \\
w_{2} \\
\vdots \\
w_{n}
\end{array}\right]=\boldsymbol{\mu}^{T} \boldsymbol{w}
$$

dengan:

$$
\boldsymbol{\mu}^{T} \text { adalah matrik transpose dari } \boldsymbol{\mu}
$$

Risiko portofolio adalah risiko investasi dari sekelompok instrumen keuangan dalam portofolio[3]. Risiko dari portofolio dapat ditulis sebagai berikut [7]:

$$
\sigma_{p}^{2}=\sum_{i=1}^{m} \sum_{j=1}^{m} w_{i} w_{j} \sigma_{i j}
$$

dengan:

$$
\sigma_{p}{ }^{2} \text { adalah risiko portofolio }
$$


$\sigma_{i j}$ adalah kovarian antara return saham $i$ dengan saham $j$

Dalam bentuk notasi matriks, risiko portofolio pada Persamaan (7) dapat ditulis sebagai berikut:

$$
\boldsymbol{\sigma}_{p}^{2}=\left[\begin{array}{llll}
w_{1} & w_{2} & \cdots & w_{n}
\end{array}\right]\left[\begin{array}{cccc}
\sigma_{11} & \sigma_{12} & \ldots & \sigma_{1 n} \\
\vdots & \vdots & \vdots & \vdots \\
\vdots & \vdots & \vdots & \vdots \\
\vdots & \vdots & \vdots & \vdots \\
\sigma_{n 1} & \sigma_{n 2} & \ldots & \sigma_{n n}
\end{array}\right]\left[\begin{array}{c}
w_{1} \\
w_{2} \\
\vdots \\
w_{n}
\end{array}\right]=\boldsymbol{w}^{T} \Sigma \boldsymbol{w}
$$

dengan:

$\Sigma$ adalah matriks varian-kovarian

\section{METODE MULTIOBJEKTIF}

Metode multiobjektif merupakan suatu metode dalam pembentukan portofolio optimal saham dengan memaksimalkan return dan meminimalkan risiko yang ekuivalen dengan meminimalkan negatif return dan meminimalkan risiko yang ekuivalen dengan meminimalkan negatif return dan risiko portofolio pada waktu bersamaan. Maka dapat ditulis sebagai berikut:

$$
\begin{gathered}
\text { Minimum: }\left(f_{1}(w), f_{2}(w)\right)=\left(-\boldsymbol{\mu}^{T} w, \boldsymbol{w}^{T} \Sigma w\right) \\
\text { Kendala: } \boldsymbol{I}^{T} \boldsymbol{w}=1 \text { dan } w \geq 0
\end{gathered}
$$

Diberikan $k_{1}=1$ dan $k_{2}=k>0$, sehingga diperoleh penyelesaian optimal sebagai berikut:

$$
\text { Minimum: }-\mu^{T} w+k w^{T} \Sigma w
$$

Kendala $\boldsymbol{I}^{T} w=1$

Permasalahan metode multiobjektif dapat diselesaikan menggunakan fungsi Lagrange Multiplier sebagai berikut[13]:

$$
L=-\mu^{T} w+k w^{T} \Sigma w+\lambda\left(I^{T} w-1\right)
$$

Persamaan (11) diturunkan terhadap $\boldsymbol{w}$, sehingga diperoleh:

$$
\boldsymbol{w}=\frac{1}{2 k} \Sigma^{-1}(\boldsymbol{\mu}-\lambda \boldsymbol{I})
$$

Persamaan (12) disubstikusikan ke $\boldsymbol{I}^{\boldsymbol{T}} \boldsymbol{w}=1$, sehingga diperoleh:

$$
\lambda=\frac{I^{T} \Sigma^{-1} \mu}{I^{T} \Sigma^{-1} I}-\frac{2 k}{I^{T} \Sigma^{-1} I}
$$

Diketahui bahwa:

$$
\begin{aligned}
& a_{1}=\boldsymbol{I}^{T} \Sigma^{-1} \boldsymbol{I} \\
& a_{2}=\boldsymbol{I}^{T} \Sigma^{-1} \boldsymbol{\mu}
\end{aligned}
$$

Sehingga diperoleh bobot saham dengan metode multiobjektif sebagai berikut:

$$
\boldsymbol{w}=\frac{1}{2 k} \Sigma^{-1} \boldsymbol{\mu}-\frac{1}{2 k} \Sigma^{-1}\left(\frac{a_{2}}{a_{1}}-\frac{2 k}{a_{1}}\right) \boldsymbol{I}
$$

dimana:

$$
a_{1} \neq 0
$$

dengan:

$\boldsymbol{w}$ adalah matriks bobot saham

$k$ adalah koefisien pembobot

I adalah matriks kolom dengan elemen 1 
$a_{1}$ dan $a_{2}$ adalah skalar

\section{VALUE AT RISK (VaR)}

VaR dapat didefinisikan sebagai estimasi kerugian maksimum yang didapat selama periode waktu (time periode) tertentu dalam kondisi pasar normal pada tingkat kepercayaan (confident interval) tertentu[2]. VaR digunakan untuk mengestimasi kerugian maksimum yang bisa saja terjadi pada esok hari, dua hari kedepan, dan seterusnya atau pada periode waktu tertentu lainnya. VaR untuk periode tertentu dirumuskan sebagai berikut[2]:

$$
\operatorname{VaR}_{(1-\alpha)}(t)=W_{0} Z_{(1-\alpha)} \sigma_{p} \sqrt{t}
$$

dengan:

$\operatorname{VaR}_{(1-\alpha)}(t)$ adalah VaR dengan tingkat kepercayaan $(1-\alpha)$ setelah $t$ periode

$W_{0}$ adalah investasi awal

$Z_{(1-\alpha)}$ adalah nilai $Z$ pada tingkat kepercayaan $(1-\alpha)$

$\sigma_{p}$ adalah risiko portofolio

$t$ adalah periode watu

\section{STUDI KASUS}

Jenis data yang digunakan dalam penelitian ini adalah data sekunder yang diperoleh dari http://finance.yahoo.com pada periode 1 Januari sampai dengan 31 Desember 2018. Data yang diambil merupakan data harga penutupan saham harian yang terdaftar pada indeks saham LQ-45. Pada kasus ini diambil contoh dengan menginvestasikan modal sebesar Rp50.000.000,00 dan diolah dengan menggunakan software SPSS 20, R i386, dan Microsoft Office Excel 2013.

Langkah pertama yang dilakukan adalah dengan menghitung return, kemudian menghitung expected return masing-masing saham. Perhitungan return dan expected return masing-masing saham dilakukan dengan menggunakan Persamaan (1) dan (2).

$$
\begin{aligned}
R_{\text {ASRI.JK } ; 2}=\ln \left(\frac{360}{356}\right) & =0,01117 \\
E\left(R_{\text {ASRI.JK }}\right) & =\frac{0,01117+(-0,01117)+0,00560+\ldots+0,00000}{260} \\
& =-0,00051
\end{aligned}
$$

Hasil keseluruhan perhitungan expected return untuk masing-masing saham dapat dilihat pada Tabel 1 berikut:

Tabel 1 Nilai Expected Return Saham

\begin{tabular}{lcrlr}
\hline \multicolumn{1}{c}{ Saham } & $\begin{array}{c}\text { Expected } \\
\text { Return }\end{array}$ & & \multicolumn{1}{c}{ Saham } & $\begin{array}{c}\text { Expected } \\
\text { Return }\end{array}$ \\
\hline ASRI.JK & $-0,00051$ & & KLBF.JK & $-0,00041$ \\
EXCL.JK & $-0,00155$ & & UNVR.JK & $-0,00080$ \\
BBCA.JK & 0,00066 & & SRIL.JK & $-0,00023$ \\
BSDE.JK & $-0,00117$ & & AALI.JK & $-0,00041$ \\
BMRI.JK & $-0,00031$ & & ICBP.JK & 0,00062 \\
PTBA.JK & 0,00215 & & LPKR.JK & $-0,00251$ \\
SSMS.JK & $-0,00070$ & & AKRA.JK & $-0,00151$ \\
\hline
\end{tabular}


Tabel 1 Nilai Expected Return Saham (Lanjutan)

\begin{tabular}{lrrrr}
\hline \multicolumn{1}{c}{ Saham } & $\begin{array}{c}\text { Expected } \\
\text { Return }\end{array}$ & & \multicolumn{1}{c}{ Saham } & $\begin{array}{c}\text { Expected } \\
\text { Return }\end{array}$ \\
\cline { 1 - 2 } \cline { 5 - 5 } SMGR.JK & 0,00058 & & ASII.JK & $-0,00003$ \\
ADHI.JK & $-0,00067$ & & SCMA.JK & $-0,00109$ \\
LPPF.JK & $-0,00223$ & & HMSP.JK & $-0,00093$ \\
WSKT.JK & $-0,00105$ & & JSMR.JK & $-0,00155$ \\
WIKA.JK & 0,00025 & & BBTN.JK & $-0,00131$ \\
MNCN.JK & $-0,00239$ & & GGRM.JK & $-0,00001$ \\
\hline
\end{tabular}

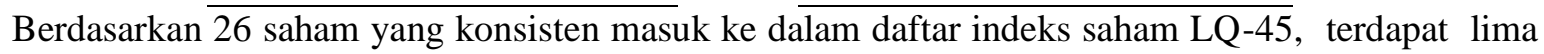
saham yang memiliki nilai expected return bernilai positif, kemudian dipilih empat saham yan memiliki nilai tertinggi. Saham yang dipilih diantaranya PTBA.JK, BBCA.JK, ICBP.JK, dan SMGR.JK.

Tahap selanjutnya adalah melakukan uji normalitas pada return saham. Asumsi dari pembentukan portofolio optimal saham menggunakan metode multiobjektif adalah return saham berdistribusi normal. Uji normalitas yang digunakan adalah uji Kolmogorov-Smirnov, dimana tingkat kesalahan $(\alpha)$ yang digunakan adalah 5\%, dengan hipotesis sebagai berikut:

$H_{0}$ : Data return saham berdistribusi normal

$H_{1}$ : Data return saham tidak berdistribusi normal

Uji normalitas return saham dengan uji Kolmogorov-Smirnov pada penelitian ini menggunakan software $\mathrm{R}$ i386. Hasil dari pengujian return saham PTBA.JK, BBCA.JK, ICBP.JK, dan SMGR.JK dapat dilihat pada Tabel 3 berikut:

Tabel 2 Hasil Uji Kolmogorov-Smirnov pada Return Saham

\begin{tabular}{lrc}
\hline \multicolumn{1}{c}{ Saham } & $\boldsymbol{p}$-value & Keputusan \\
\hline PTBA.JK & 0,592 & $H_{0}$ diterima \\
BBCA.JK & 0,284 & $H_{0}$ diterima \\
ICBP.JK & 0,386 & $H_{0}$ diterima \\
SMGR.JK & 0,284 & $H_{0}$ diterima \\
\hline
\end{tabular}

Berdasarkan hasil pengujian Kolmogorov-Smirnov pada Tabel 2, dapat diketahui bahwa return saham PTBA.JK, BBCA.JK, ICBP.JK, dan SMGR.JK menghasilkan $p$-value yang lebih dari $\alpha(5 \%)$. Maka diperoleh keputusan $H_{0}$ diterima yang artinya return saham berdistribusi normal.

Data return saham PTBA.JK, BBCA,JK, ICBP.JK, dan SMGR.JK memenuhi asumsi dari metode multiobjektif, sehingga dilanjutkan dengan tahap menghitung nilai bobot masing-masing saham. Pada metode multiobjektif terdapat koefisien pembobot yang digunakan untuk menunjukkan seberapa besar seorang investor mengambil risiko atas expected return. Nilai koefisien pembobot digunakan sebagai indikator risiko. Nilai koefisien pembobot yang kecil menunjukkan tingkat risiko yang ditanggung tinggi, semakin besar nilai koefisien pembobot menunjukkan tingkat risiko yang ditanggung rendah. Koefisien pembobot yang digunakan dalam penelitian ini adalah $k=10$.

Perhitungan bobot portofolio optimal saham dengan metode multiobjektif dilakukan dengan menggunakan Persamaan (14). Hasil perhitungan bobot masing-masing saham dapat dilihat pada Tabel 3 berikut:

\begin{tabular}{cr}
\multicolumn{2}{c}{ Tabel 3 Nilai Bobot Saham } \\
\hline \multicolumn{1}{c}{ Saham } & Bobot \\
\hline PTBA.JK & 23,356 \\
BBCA.JK & 45,220 \\
ICBP.JK & 27,432 \\
SMGR.JK & 3,991 \\
\hline
\end{tabular}


Tabel 3 menunjukkan besarnya proporsi masing-masing saham. Diketahui bahwa bobot terbesar pada saham BBCA.JK, yaitu sebesar 45,220 dan bobot terkecil pada saham SMGR.JK, yaitu sebesar 3,991 .

Setelah mengetahui nilai bobot masing-masing saham, selanjutnya menghitung nilai expected return portofolio. Perhitungan expected return portofolio dilakukan dengan menggunakan Persamaan (6).

$$
\begin{aligned}
E\left(R_{p}\right) & =0,00215(0,23356)+0,00066(0,45220)+\ldots+0,00058(0,03991) \\
& =0,09925
\end{aligned}
$$

Berdasarkan perhitungan yang dilakukan, dapat diketahui bahwa nilai expected return dari portofolio optimal yang tebentuk adalah 0,09925. Artinya, jika investor menginvestasikan dana sebesar Rp50.000.000,00, maka investor bisa mendapatkan expected return sebesar Rp4.962.680,00

Selain menghitung nilai expected return portofolio, dihitung pula nilai risiko portofolio dengan menggunakan VaR. Perhitungan VaR portofolio dilakukan dengan menggunakan Persamaan (15). Tingkat kepercayaan yang digunakan adalah sebesar $95 \%$ dengan periode waktu 20 hari.

$$
\begin{aligned}
\operatorname{VaR}_{(1,645)}(20) & =(\operatorname{Rp} 50.000 .000,00)(1,645)(0,012)(\sqrt{20}) \\
& =R p 4.352 .279,00
\end{aligned}
$$

Berdasarkan perhitungan yang dilakukan, dapat diketahui bahwa nilai VaR sebesar Rp4.352.279,00. Hal ini dapat diartikan ada keyakinan sebesar $95 \%$ bahwa kerugian yang diperoleh investor tidak akan melebihi Rp4.352.279,00 dalam jangka waktu 20 hari.

\section{PENUTUP}

Berdasarkan hasil analisis yang telah dilakukan peneliti pada saham PTBA.JK, BBCA.JK, ICBP.JK, dan SMGR.JK untuk periode 1 Januari sampai dengan 31 Desember 2018 menggunakan metode multiobjektif dengan koefisien pembobot $k=10$, dapat disimpulkan bahwa jika menginvestasikan modal sebesar Rp50.000.000,00 dengan periode waktu 20 hari dan pada tingkat kepercayaan 95\% , maka nilai return yang diperoleh sebesar Rp4.962.680,00 dengan risiko sebesar Rp4.352.279,00.

\section{DAFTAR PUSTAKA}

[1] Martalena dan Malinda M. Pengantar Pasar ModaL. Yogyakarta: Andi Publisher; 2011.

[2] Jorion P. Value at Risk: The New Benchmark Managing Financial Risk Ed ke-3. New York: The McGraw-Hill Companies Inc; 2007

[3] Hartono J. Teori Portofolio dan Analisi Investasi Ed ke-7. Yogyakarta: BPFE; 2010

[4] Steuer RE, Qi Y, dan Hirschberger M. Multiple Objectives in Portfolio Selection. Journal of Financial Decision Making. 2005; (1):11-26.

[5] Herlianto D. Manajemen Investasi Plus Jurus Mendeteksi Investasi Bodong. Yogyakarta: Gosyen Publishing; 2013.

[6] Hull JC. Options, Futures, and Other Derivatives Ed ke-7. Toronto: Prentice Hall International Inc; 2009.

[7] Hartono J. Teori Portofolio dan Analisis Investasi Ed ke-11. Yogyakarta: BPFE; 2017.

[8] Sutarno YA, Maruddani D, dan Sugito. Valuasi Compound Option Put on Put Tipe Eropa. Jurnal Gaussian. 2014; (3):509-518.

[9] Chakraborti S dan Gibbons JD. Nonparametric Statistical Inference Ed ke-4. New York: Marcel Dekker Inc; 2005.

[10] Hartono J. Teori dan Praktik Portofolio dengan Excel. Jakarta: Salemba Empat; 2014.

[11] Tandelilin E. Portofolio dan Investasi: teori dan aplikasi Ed ke-1. Yogyakarta: Kanisius; 2010.

[12] Farkhati F, Hoyyi A, dan Wilandari Y. Analisis Pembentukan Portofolio Optimal Saham 
dengan Pendekatan Optimisasi Multiobjektif untuk Pengukuran Value at Risk. Jurnal Gaussian. 2014; (3):371-380.

[13] Duan YC. A Multi-Objective Approach to Portfolio Optimization. Rose-Hulman Undergraduate Mathematics Journal. 2007; (8):1-18.

DWI NINING INDRASARI : Jurusan Matematika FMIPA UNTAN, Pontianak indrasaridn@gmail.com

NEVA SATYAHADEWI : Jurusan Matematika FMIPA UNTAN, Pontianak neva.satya@math.untan.ac.id

HENDRA PERDANA : Jurusan Matematika FMIPA UNTAN, Pontianak hendra.perdana@math.untan.ac.id 